\title{
A Simple Numerical Example Illustrating Flexible versus Inflexible Manufacturing Systems
}

\author{
Gerald Aranoff \\ Ariel University, Ariel, Israel \\ Email: garanoff@netvision.net.il
}

How to cite this paper: Aranoff, G. (2018) A Simple Numerical Example Illustrating Flexible versus Inflexible Manufacturing Systems. Modern Economy, 9, 241-246. https://doi.org/10.4236/me.2018.91015

Received: December 22, 2017

Accepted: January 22, 2018

Published: January 25, 2018

Copyright $\odot 2018$ by author and Scientific Research Publishing Inc. This work is licensed under the Creative Commons Attribution International License (CC BY 4.0).

http://creativecommons.org/licenses/by/4.0/

\begin{abstract}
Flexible manufacturing system is a wonderful development in manufacturing technology that permits a modern factory to switch easily to making different products. I present a simple numerical example to illustrate flexible manufacturing system $(\mathrm{K})$ and inflexible manufacturing system $(\mathrm{L}) . \mathrm{K}$ can produce product 1 or product 2 with the same machinery and with zero setup costs in changing output from product 1 to 2 or from product 2 to 1 . L can produce only one product, product 2 . I assume large numbers of producers and buyers of products 1 and 2, open market systems, each acting to his/her interest to secure profits and consumer welfare with minimal government interference/ regulation. I assume both $\mathrm{K}$ and $\mathrm{L}$ have linear total costs with absolute capacity limits. If prices are above SRMC then plants produce at capacity. Producers are price takers only. If price equals or below SRMC plants shutdown. I assume demand for products 1 and 2 are random and alternate, meaning never at the same. I assume ease of entry/exit of producers. Long-run equilibrium requires zero expected profits for all producers.
\end{abstract}

\section{Keywords}

Flexible Manufacturing System

\section{Introduction: Flexible Manufacturing System}

\subsection{Exciting New Development in Manufacturing Technology}

A flexible manufacturing system is a manufacturing system in which there is flexibility that allows the system to react to changes, whether predicted or unpredicted. This flexibility falls into two categories. The first category, routing flexibility, covers the system's ability to produce new product types, and to 
change the order of operations executed on a part. The second category is called machine flexibility, which consists of the ability to use multiple machines to perform the same operation on a part, as well as the system's ability to absorb large-scale changes, such as in volume or capability. In my simple numerical example of flexible versus inflexible manufacturing system, $\mathrm{K}$ versus $\mathrm{L}, \mathrm{K}$ is a flexible manufacturing system because it can it easily switch from making product 1 to making 2 and visa versa. $\mathrm{L}$ is an inflexible manufacturing system because it can manufacture only product 2 .

The flexible manufacturing system is an exciting new development in manufacturing technology: to increase manufacturing flexibility, to easily switch from between products manufactured. My numerical example demonstrates convincingly the superiority of the flexible manufacturing system. Researchers in production and manufacturing praise the flexible manufacturing system ${ }^{1}$.

\subsection{My Numerical Example}

In my numerical example, for simplification, I assume demand schedules for product 1 and 2 are identical. I assume that flexible manufacturing system has lower variable costs, VC, per unit and higher fixed costs, FC, per period than the inflexible manufacturing system. I assume the flexible manufacturing system has the same VC and FC, for products 1 and 2.

\subsection{A World of Globalization}

Today we live in a world of globalization. I write²:

Globalization is a process of interaction and integration among the people, companies, and governments of different nations, a process driven by international trade and investment and aided by information technology. Globalization increases under open-market systems domestically and internationally. Countries under open-market systems have large numbers of producers and buyers of goods and services each acting to his/her interest to secure profits and consumer welfare with minimal government interferrence/regulation.

In a world of globalization, there is an urgent need for the flexible manufacturing system, whereby a factory can easily switch making product 1 to making product 2 to making product 3 etc.

\subsection{John M. Clark on Wastes of Idle Capacity}

John M. Clark wrote in 1923 that the secret of efficiency is price discrimination ${ }^{3}$

"If one had to choose a motto of six words, expressing the most central economic consequence of overhead cost, the first choice might fall upon some such phrase as : "Full utilization is worth its cost," but a close second ${ }^{1}$ See Chan et al. [1].

${ }^{2}$ Aranoff, Gerald, "Globalization: Alternative Pricing in a Peak-Load Pricing Model," Modern Economyvol, 8 July 2017 [2].

${ }^{3}$ Clark, page 416 [3]. 
would be: "Discrimination is the secret of efficiency." This last, to be sure, needs to be taken with a proviso: one must know where to stop. The economic basis of it is simple. Existing business may or may not cover all overhead costs, but in either case, if there is spare capacity, added business will cause no added overhead, and will be a gain at anything above differential cost, so long as it can be kept separate from existing business, so that existing earnings are not impaired."

Clark argued that a factory gains in efficiency if the factory can more fully utilize its capacity. Clark wrote much on the waste of idle capacity. Today, with computers and robots etc., the flexible manufacturing system aims to minimize waste of idle capacity. This is the benefit of the flexible manufacturing system.

\section{Numerical Example: Inflexible versus Flexible Manufacturing System}

I model choice between flexible manufacturing system and inflexible manufacturing system by considering two hypothetical plants investors could choose, plant $_{K}$ and plant ${ }_{L}$. Both plants have durable assets and linear short-run total costs curves with absolute capacity limits. The plants differ in per-unit operating cost, $b$, per-unit capacity cost, $\beta$, and capacity per plant, $q$. My notation is that $b$ is the constant per-unit variable operating cost. $\beta$ is the per-unit fixed capacity cost where the numerator is the constant fixed costs per week and the denominator is the maximum the plant can produce in a week. I assume periods of a week. I assume $\mathrm{q}$ is the operating rate. Let $n$ be the number of plants, a continuous variable.

I assume $b_{K}<b_{L}, \beta_{K}>\beta_{L}$, and $q_{L}>q_{K}{ }^{4}$. Investors cannot choose a mixture of plant $_{K}$ and plant ${ }_{L}$. The industry will comprise of only plants ${ }_{K}$ or only plants $_{L}$. If investors could choose a mixture of plant ${ }_{K}$ and plant $_{L}$, then plant ${ }_{K}$

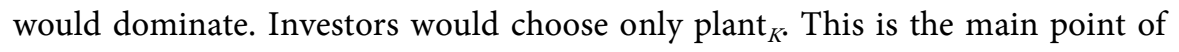
the numerical example.

Demand fluctuates between $P_{1}$ with frequency $w_{1}$ and $P_{2}$ with frequency $w_{2}$. Expected total revenues $=E(T R)=P_{1} w_{1}+P_{2} w_{2}$. Expected total costs $=$ $E(T C)=S T C_{1} w_{1}+S T C_{2} w_{2}$. Expected profits $=E(\pi)=E(T R)-E(T C)$. Long-run equilibrium requires $E(\pi) \approx 0$.

For simplification in my numerical example, let:

$$
\begin{aligned}
& b_{1 K}=\$ 24 \text { per ton } t_{1}=b_{2 K}=\$ 24 \text { per } \text { ton }_{2} \\
& \beta_{1 K}=\$ 12 \text { per } \text { ton }_{1}=\beta_{2 K}=\$ 12 \text { per } \text { ton }_{2} \\
& q_{1 K}=0.72 \text { ton }_{1} \text { per week }=q_{2 K}=0.72 \text { ton }_{2} \text { per week } \\
& b_{2 L}=\$ 31.2 \text { per ton } 2 \\
& \beta_{2 L}=\$ 4.8 \text { per } \text { ton }_{2} \\
& q_{2 L}=0.9 \text { ton }_{2} \text { per week } \\
& w_{1}=w_{2}=0.5 \\
& P_{1}=3456 / Q_{1} w_{1}
\end{aligned}
$$

${ }^{4}$ As in my Economic Modelling article [4]. 


$$
P_{2}=3456 / Q_{2} w_{2}
$$

Plant $_{K}$ illustrates flexible manufacturing system because it can switch between making product 1 and 2 with infinite ease. Plant ${ }_{L}$ illustrates inflexible manufacturing system because it can make only product 2 . Fractional plants are permitted. No long-run economies of scale are assumed for each plant.

Figure 1 shows inflexibile manufacturing system with only plants manufac- $_{L}$ turing product 2. The industry capacity is 84.7 tons $_{2}$ per week from 94.11 plants $_{2 L}$. Long run equilibrium exists because industry demand for product 2 is satisfied and expected profits over the cycle are 0.

Figure 2 shows flexible manufacturing system with industry capacity, if

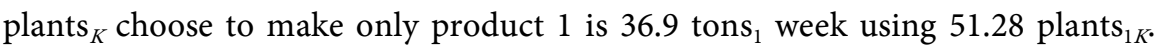
Industry capacity, if plants ${ }_{K}$ choose to make only product 2 is 84.7 tons $_{2}$ per week using 117.65 plants $_{2 K}$.

Figure 3 shows the numerical example plant ${ }_{K}$ flexible manufacturing system which can switch instantly with no setup cost from making one product to making another product, versus plant ${ }_{L}$ which can manufacture only product 2 . Plant $_{L}$ shuts down in $w_{1}$ when there is no demand for product 2 . The flexible manufacturing system will dominate, especially as in real cases, flexible manufacturing systems can switch among more than two products.

\section{Conclusions and Policy Implication}

\subsection{A Quantum Leap Forward in Manufacturing}

Flexible manufacturing system is quantum leap forward in manufacturing. My earlier work on output-flexibility ${ }^{5}$ presumes old-fashioned factories as in John

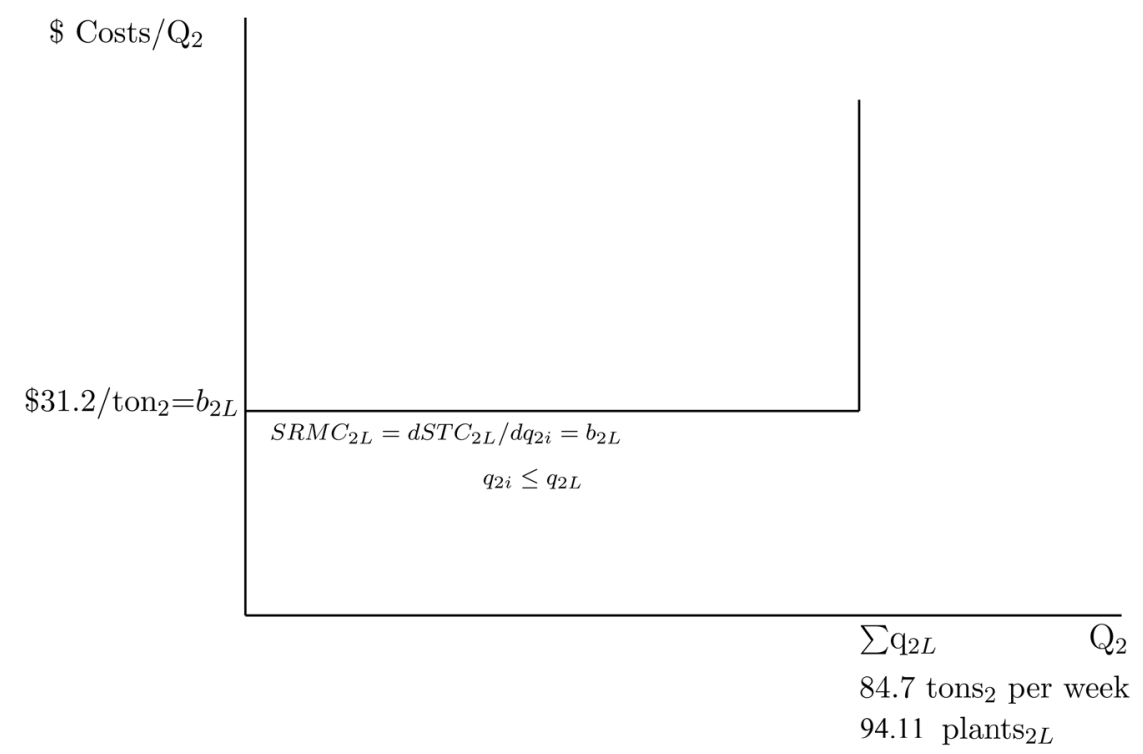

Figure 1. $\sum M C_{L} / Q_{2}$ Inflexible Manufacturing System.

${ }^{5}$ Aranoff, Gerald, "Competitive Manufacturing with Fluctuating Demand and Diverse Technology: Mathematical Proofs and Illuminations on Industry Output-Flexibility," Economic Modelling vol, 28 May 2011 1441-1450 [4]. 


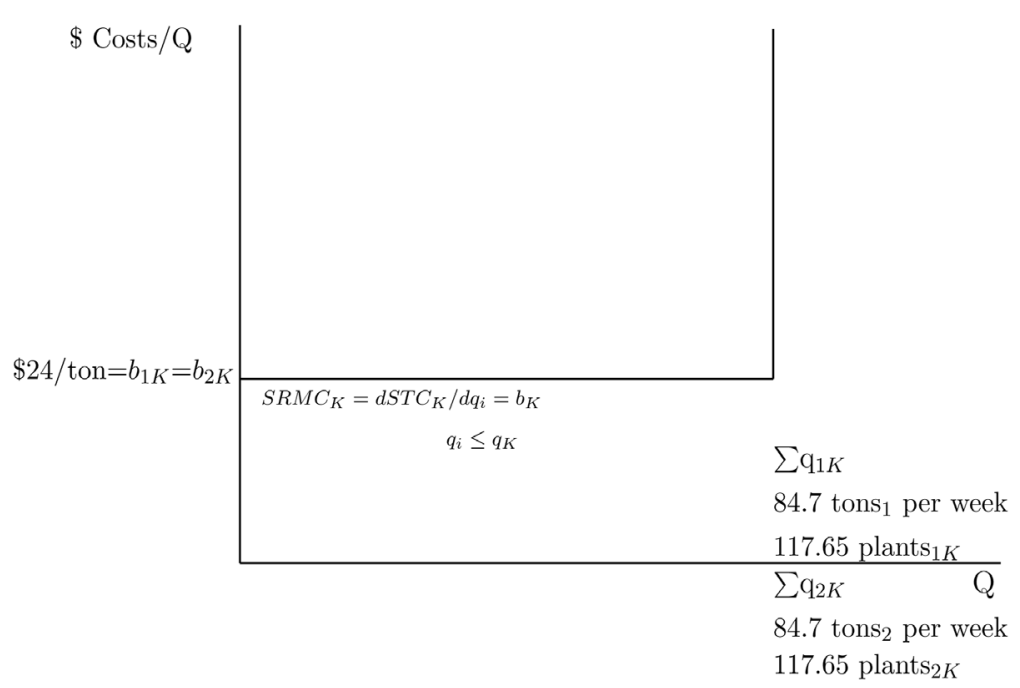

Figure 2. $\sum M C_{K} / Q_{2}+\sum M C_{K} / Q_{1}$ Flexible Manufacturing System.

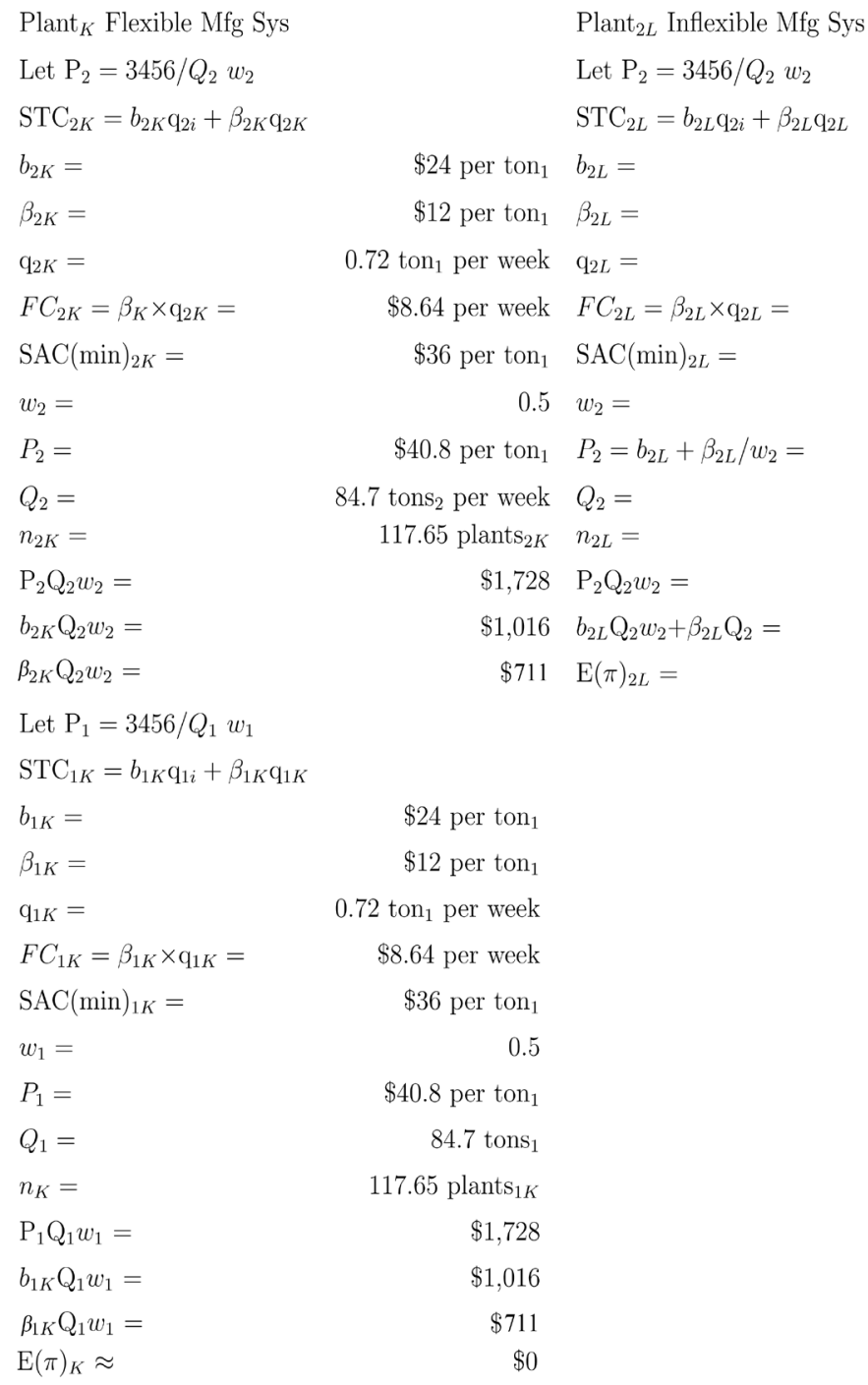

$\$ 31.2$ per ton 2

$\$ 4.8$ per ton 2 0.9 tons $_{2}$ per week

$\$ 4.32$ per week

$\$ 36$ per ton 2

0.5

\$40.8 per ton 2 84.7 tons $_{2}$ per week

94.11 plants $_{2 L}$

$\$ 1,728$

$\$ 1,728$

$\$ 0$

Figure 3. Flexible versus Inflexible Manufacturing System. 
M. Clark's days. Investors will want to invest in plant capacity that has a flexible manufacturing system that will enable the factory to operate at a higher rate of utilization.

\subsection{Steel Makers Adopting Flexible Manufacturing System}

Recent WSJ article ${ }^{6}$.

"Steel makers are betting on the US again, building mills they hope will help them compete against cheap imports as demand rises... The company says the mill can be adapted to produce different flat-rolled steel products, potentially leaving it less vulnerable to supply gluts than mills making just one or two products."

\subsection{More Complex Computer Models Needed}

My simple numerical example can help companies making complex computer models of proposed plant expansion, construction, or renovation. Today, with globalization, intense worldwide competition, and technological developments, there is much uncertainty on exactly which products a company should make. Computer models will aid decision making. The flexible manufacturing system may justify capital expenditures where an inflexible manufacturing system could not be justified. Companies must have a flexible manufacturing system to prosper.

\section{References}

[1] Chan, Felix, T.S., Bhagwat, R. and Wadhwa, S. (2008) Comparative Performance Analysis of a Flexible Manufacturing System (FMS): A Review-Period-Based Control. International Journal of Production Research, 46, 1-24.

[2] Aranoff, G. (2017) Globalization: Alternative Pricing in a Peak-Load Pricing Model. Modern Economy, 888-896. https://doi.org/10.4236/me.2017.87062

[3] Maurice, C.J. (1923) Studies in the Economics of Overhead Costs. The University of Chicago Press, Chicago.

[4] Aranoff, G. (2011) Competitive Manufacturing with Fluctuating Demand and Diverse Technology: Mathematical Proofs and Illuminations on Industry OutputFlexibility. Economic Modelling, 1441-1450.

https://doi.org/10.1016/j.econmod.2011.02.016

${ }^{6}$ https://www.wsj.com/articles/u-s-steelmakers-raise-their-bets-on-energy-construction-1514635200. 